\title{
Challenges of Detecting Lead in Drinking Water Using at-Home Test Kits
}

\author{
Rebecca Kriss, Kelsey J. Pieper,* Jeffrey Parks, and Marc A. Edwards* \\ Cite This: Environ. Sci. Technol. 2021, 55, 1964-1972 \\ Read Online
}

ABSTRACT: Lead in drinking water remains a significant human health risk. At-home lead in water test kits could provide consumers with a convenient and affordable option to evaluate this risk, but their accuracy and reliability is uncertain. This study examined the ability of at-home lead test kits to detect varying concentrations of dissolved and particulate lead in drinking water. Sixteen brands representing four test kit types (binary color, binary strip, colorimetric vial, and color strip) were identified. Most kits (12 of 16 brands) were not suitable for drinking water analysis, with lead detection limits of 5-20 mg/L. Binary strips detected dissolved lead at drinking water-relevant levels but failed to detect particulate lead. Household acids (lemon juice and vinegar) improved the strip's ability to detect lead by dissolving some of the lead
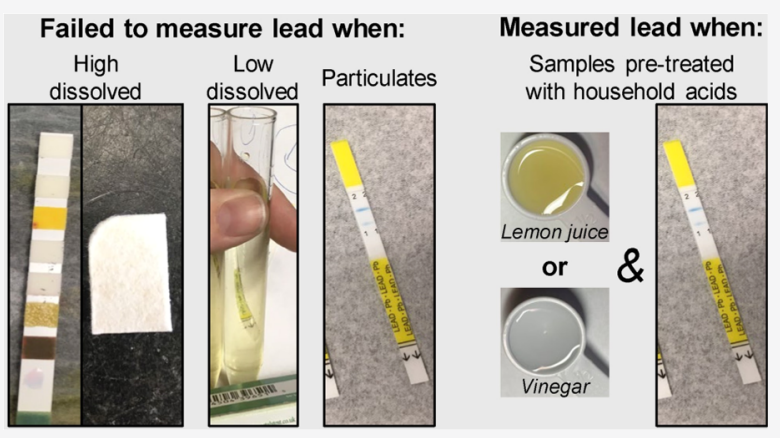
particulates to the point soluble lead exceeded $15 \mu \mathrm{g} / \mathrm{L}$. These results illustrate the applications of at-home testing kits for drinking water analysis, highlight limitations and areas for possible improvement, and put forth a testing protocol by which new at-home lead test kits can be judged.

\section{INTRODUCTION}

Lead in drinking water remains a significant human health risk, as evidenced by recent cases of water-related elevated blood lead ${ }^{1-4}$ and thousands of community systems with Lead and Copper Rule (LCR) violations. ${ }^{5}$ There are well-known weaknesses in the protection offered to individual homes under the LCR. Weaknesses include improper sampling methods and analytical procedures that can miss water lead hazards, as well as the provision that allows up to $10 \%$ of the high risk homes tested to have very high water lead without triggering public notification. ${ }^{6,7}$ Although problems with high lead at a given tap are frequently viewed as government or regulatory failures, it is important to note that the LCR was not designed to protect every consumer at every tap-rather, it aims to reduce the magnitude and frequency of lead in water problems systemwide. ${ }^{6,8,9}$ This leaves residents with a share of the responsibility to identify and address their lead in water problems.

Portable and consumer-centric tools are urgently needed to enable residents to meet that responsibility, but there is an important balance between convenience and data quality that must be understood. ${ }^{10}$ On-site testing using spectrophotometric, fluorescence-based methods and anodic stripping voltammetry (ASV) analysis has been explored because of their portability, fast results, relative ease of use, and low costs. ${ }^{10-12}$ However, these tests may be subject to interferences from other analytes in water and may not detect particulate lead without adding an acidification step, thereby underestimating total lead in drinking water. ${ }^{7,10-12}$ While these technologies have lower capital costs than laboratory testing, costs can still be significant when factoring in the price per sample (about $\$ 10$ plus labor cost) and the portable ASV unit cost (about \$1000-2000). ${ }^{10,11}$ Moreover, the US Environmental Protection Agency (US EPA) recommends that users exercise caution when choosing a field testing technology, as some analyzers use dangerous consumables and reagents, and require technical skills. This makes them better suited for researchers and utilities, so they are not recommended or are poorly suited for use by residents. ${ }^{10,12,13}$ In contrast, low-cost commercially available at-home lead in water test kits may provide a good alternative for consumers; however, there has been limited research into their efficacy, so their accuracy and reliability are uncertain. Several organizations (e.g., Good Housekeeping Institute, Consumer Reports) have evaluated these commercially available at-home kits, but these are not systematic evaluations and they failed to evaluate the expected problems associated with detecting particulate lead. ${ }^{14,15}$

Distrust of drinking water quality, which increased in the aftermath of the Flint water crisis, has resulted in tap water avoidance which has significant health and economic

Received: November 10, 2020

Revised: December 22, 2020

Accepted: December 23, 2020

Published: January 11, 2021

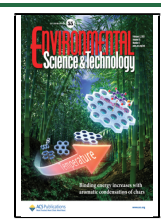




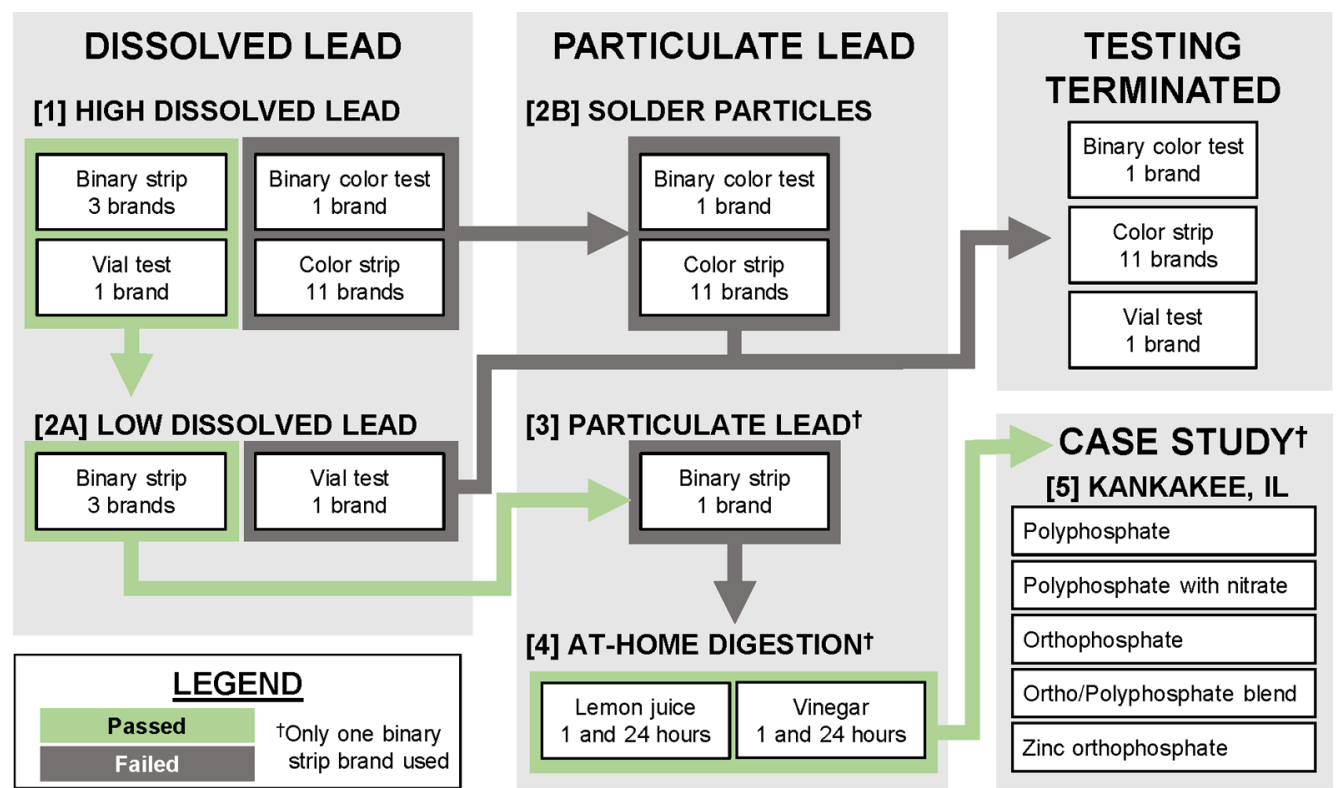

Figure 1. Phases of lead in water testing used to evaluate test kits' ability to detect or measure dissolved and particulate lead.

implications. ${ }^{16-18}$ The use of a low-cost, accurate at-home lead in water test kit could increase the confidence in tap water quality and help address water insecurity in at-risk communities. This study explored the accuracy and precision of commercially available at-home lead in drinking water test kits when exposed to varying water conditions. Specifically, the objectives of this study were to (1) identify available at-home test kits that measured lead in water; (2) examine the ability of test kits to detect different concentrations of dissolved and particulate lead in water; and (3) characterize the ability of test kits to detect solder particles, reported to be relatively recalcitrant, ${ }^{19}$ exposed to water with different corrosion control treatments. This is the first scientific study assessing the accuracy and precision of a range of available at-home lead in water test kits that are commercially available and in use despite the lack of scientific validation or certification. Moreover, as new test kits become available, the testing protocol outlined in this study can serve as a metric to ensure that the kits can accurately detect lead in drinking water.

\section{METHODS}

2.1. Test Kit Selection. An Amazon search for "water lead test kit" was performed on May 9, 2018. This search yielded 347 products, of which $122(35.1 \%)$ measured lead in water (Supporting Information Figure S1). After removing duplicates, 34 unique test kits were identified. This study examined at-home test kits, so spectrophotometric $(n=1)$ and mail-away tests $(n=8)$ were removed. The remaining test kits were categorized into four groups (Figure S2): (1) binary strips $(n=$ 8 ), which indicate lead detection based on the appearance of lines, and color-based tests including: (2) colorimetric vial tests $(n=1),(3)$ binary color tests $(n=1)$, and (4) color strips $(n=$ $15)$, which indicated lead detection or concentration based on color changes. Four brands of color strips would have been included but were not available at the time of purchase. Upon purchase, we discovered that seven of the binary strip brands had identical interior packaging ( 5 of one type and 2 of another type). This suggested that the same testing materials were being used among several brands; therefore, three brands were chosen to represent the three unique binary strip testing materials identified. The remaining 16 test kits were evaluated: 3 binary strip, 1 colorimetric vial test, 1 binary color test, and 11 color strip brands. The detection levels of these test kits were $15,20,5000$, and $20,000 \mu \mathrm{g} / \mathrm{L}$, respectively.

2.2. Testing Approach. Testing was performed according to the manufacturers' instructions. Each brand was tested in triplicate, and one blank control was included for each water condition per phase (Figure 1). The base water condition was a modified version of the NSF/ANSI $53 \mathrm{pH} 8.5$ water, ${ }^{20}$ with dissolved lead added as $\mathrm{Pb}\left(\mathrm{NO}_{3}\right)_{2}$ and particulate lead as described below. Testing was conducted within $1 \mathrm{~h}$ of adding dissolved lead and $30 \mathrm{~min}$ of adding particulate lead. To determine the accuracy and precision of the test kits, a tiered testing approach was developed. Specifically, the test kits were exposed to high dissolved lead (Phase 1) and, based on their performance, were exposed to low dissolved lead (Phase 2A) or solder particles (Phase $2 \mathrm{~B}$ ). Kits that were successful in Phase 2A were tested in Phases 3-5 with particulate lead.

Six participants were recruited to read measurements for the high dissolved lead experiments (Phase 1). Results for lead concentrations were calculated based on the average of the triplicate tests for each of the participants. Only one participant read results for the other experiments (Phases 2-5), which focused primarily on the binary strips. Overall, participants were not confident in their ability to read the lead measurements (Section S1), but the binary strips had consistent readings among participants based on the presence/absence metric.

2.2.1. Dissolved Lead. All 16 test kits were evaluated in Phase 1 to determine if they could measure or detect a relatively high dissolved lead concentration $(150 \mu \mathrm{g} / \mathrm{L})$. The four test kits ( 1 colorimetric vial test and 3 binary strip brands) that accurately characterized high dissolved lead were then evaluated in Phase $2 \mathrm{~A}$ to determine if they could detect low dissolved lead $(5,10$, and $20 \mu \mathrm{g} / \mathrm{L})$ near the US EPA action level.

2.2.2. Particulate Lead. The 12 test kits that did not accurately characterize high dissolved lead in Phase 1 ( 1 binary color and 11 color strip test brands) were evaluated in Phase $2 \mathrm{~B}$ to determine if they could measure or detect an extremely 


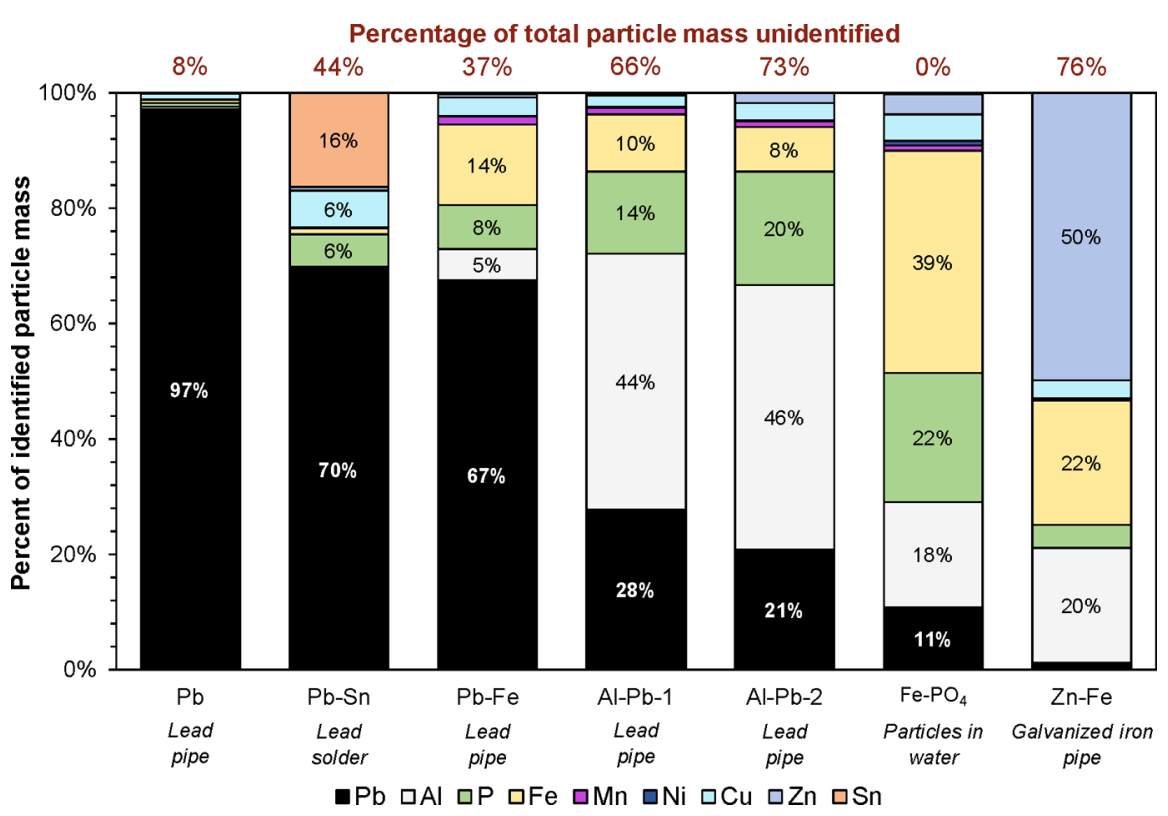

Figure 2. Metal composition for one particle sample of each type ( $5 \mathrm{mg}$ dry particles added to $1 \mathrm{~L}$ of water or particles collected in water) based on the total recovered particle mass. Data labels are not included for metals that represent $<5 \%$ of the particle composition.

high level of particulate lead, which was well above their detection limits. Lead solder particles were added to the base water to produce a lead concentration of $50 \mathrm{mg} / \mathrm{L}$.

Three binary strip brands detected low dissolved lead in Phase 2A, but only one brand (Brand 1) was selected for testing in Phases 3 and 4, to determine if the binary strips could detect various types of particulate lead in water. Brand 1 was selected for this additional testing because it consistently detected lead at $10 \mu \mathrm{g} / \mathrm{L}$.

All particle samples, except for the particles from Cicero, IL $\left(\mathrm{Fe}-\mathrm{PO}_{4}\right)$, were collected as dry particles from pipe surfaces and added $(5.0 \pm 0.8 \mathrm{mg})$ to $1 \mathrm{~L}$ of the base water amended with $1 \mathrm{mg} / \mathrm{L}$ phosphate as $\mathrm{P}$ to reduce dissolution in water. The Cicero, IL particles were tested in the municipal tap water in which they were collected, which had a phosphate concentration of $0.31 \mathrm{mg} / \mathrm{L}$ as $\mathrm{P}$. Representative lead particles (range of \% lead content of total recovered particle mass from $n=3-4$ samples; particle name) were derived from (1) lead pipe from a laboratory experiment $(92 \rightarrow 99 \% \mathrm{~Pb} ; \mathrm{Pb}) ;^{21}(2)$ a solder joint extracted from a Flint, MI home $(42-70 \% \mathrm{~Pb}$; $\mathrm{Pb}-\mathrm{Sn}) ;$ (3) lead pipe from Washington, DC (55-67\% $\mathrm{Pb}$; $\mathrm{Pb}-\mathrm{Fe}) ;(4)$ lead pipe from Buffalo, $\mathrm{NY}(23-30 \% \mathrm{~Pb} ; \mathrm{Al}-\mathrm{Pb}-$ 1); (5) lead pipe from Flint, $\mathrm{MI}(9-27 \% \mathrm{~Pb} ; \mathrm{Al}-\mathrm{Pb}-2) ;(6) \mathrm{a}$ water sample from Cicero, IL (3-14\% $\left.\mathrm{Pb} ; \mathrm{Fe}-\mathrm{PO}_{4}\right)$; and (7) a galvanized iron pipe from resident zero in Flint, MI (0.8$1.4 \% \mathrm{~Pb} ; \mathrm{Zn}-\mathrm{Fe})^{22}$ (Table S1; Figure 2). The total recovered particle masses across all samples were $24-97 \%$ of the total particle mass added, with the remainder attributable to incomplete particle dissolution and/or mass from constituents such as oxygen and carbon that were not detected (Table S2). To illustrate the variable composition across particle types, Figure 2 presents the composition and mass recovery for one of the 3-4 samples per particle type used in this analysis. Section S2 provides an overview of particle characterization to determine lead content.

Particle size distributions were determined for dry particles via Raman atomic force microscopy (WITec AFM-Raman). Images at $4 \times$ and $40 \times$ magnifications were analyzed using ImageJ software (National Institute of Health) to count particles of varying sizes, with a threshold of four pixels to reduce image noise resulting from color threshold adjustment. Representative images for dry particles from Phases $2 \mathrm{~B}$ and 3 are presented in Figure S3.

Since the binary strip could not detect lead particles, experiments were conducted to determine if common household acids (i.e., vinegar and lemon juice) could improve detection by dissolving lead particles in Phase 4 . A dose of 41 $\mathrm{mL}$ of lemon juice or vinegar per $1 \mathrm{~L}$ of the water condition was added and digestion occurred for $1 \mathrm{~h}$ and $24 \mathrm{~h}$.

2.2.3. Case Study. Lead solder particles are sometimes more difficult to dissolve than other lead particles. ${ }^{19}$ Therefore, lead particles were formed by exposing lead solder to a base water with different types of phosphate inhibitors, and binary strip detection was evaluated with and without at-home dissolution (Phase 5). Finished drinking water from the Kankakee River (Table S3) was used to create a more realistic relationship between dissolved and particulate lead observed in drinking water. In brief, finished drinking water was shipped to Virginia Tech, where it was blended with synthetic water in a 2:1 ratio and the $\mathrm{pH}$ was adjusted to 8.2. Incorporating the synthetic water increased the chloride to sulfate mass ratio to 0.76 , which created a water condition scenario with higher potential for galvanic corrosion. ${ }^{4}$ Lead solder joints were exposed to the blended water with five CCT strategies: (1) polyphosphate $(0.8 \mathrm{mg} / \mathrm{L}$ as $\mathrm{P})$; (2) polyphosphate with nitrate $(0.8 \mathrm{mg} / \mathrm{L}$ polyphosphate as $\mathrm{P}, 3 \mathrm{mg} / \mathrm{L}$ nitrate); (3) orthophosphate (1 $\mathrm{mg} / \mathrm{L}$ as P); (4) 90:10 orthophosphate/polyphosphate blend $(1 \mathrm{mg} / \mathrm{L}$ as $\mathrm{P})$; and $(5)$ zinc orthophosphate $(0.5 \mathrm{mg} / \mathrm{L} \mathrm{Zn}$ and $1 \mathrm{mg} / \mathrm{L}$ orthophosphate as $\mathrm{P})$. In addition, an amended control (blended water with no inhibitors) and an unamended control (finished drinking water with no inhibitors) were analyzed. Prior to sampling, all coupons were conditioned using a daily dump-and-fill protocol for (1) four days with $\mathrm{pH}$ 8 water with $2 \mathrm{mg} / \mathrm{L}$ chlorine as $\mathrm{Cl}_{2}$ and an alkalinity of 500 $\mathrm{mg} / \mathrm{L}$ as $\mathrm{CaCO}_{3}$ from sodium bicarbonate, (2) 12 days of conditioning using finished drinking water, and (3) 36 days of conditioning using their water condition. After conditioning, a composite water sample was collected from each water 


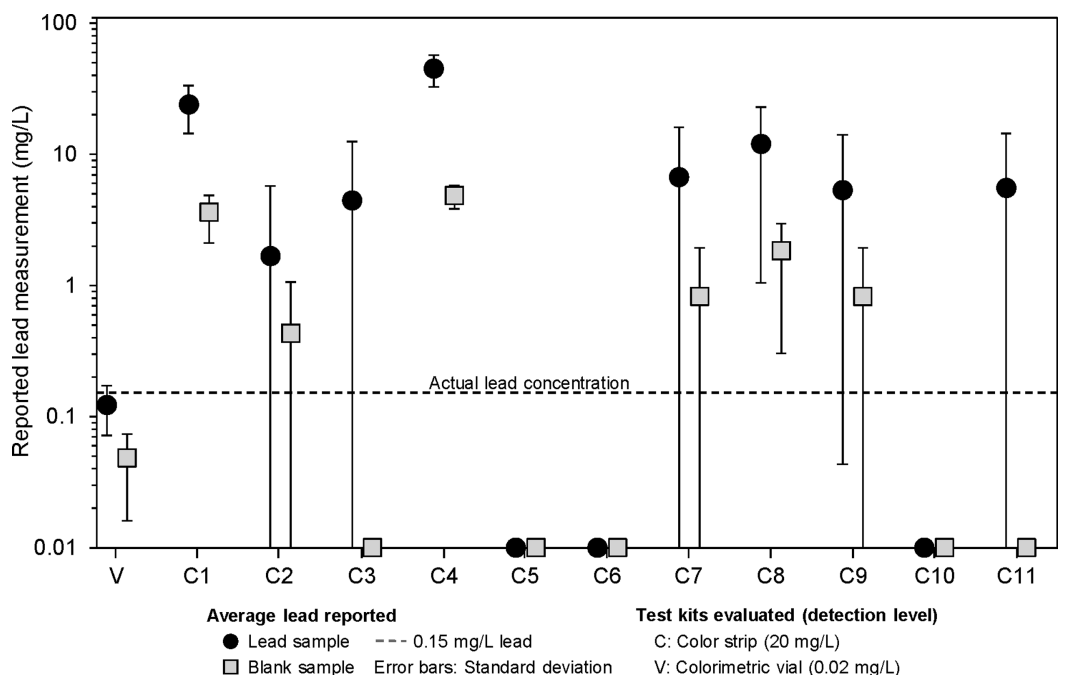

Figure 3. Average lead reported by participants for at-home tests with numeric results ( 1 colorimetric vial test and 11 brands of color strips) when measuring (1) $150 \mu \mathrm{g} / \mathrm{L}$ dissolved lead (black circles) $(n=6)$ and (2) blank (grey squares) $(n=6)$. Error bars represent standard deviations of averaged results from participants.
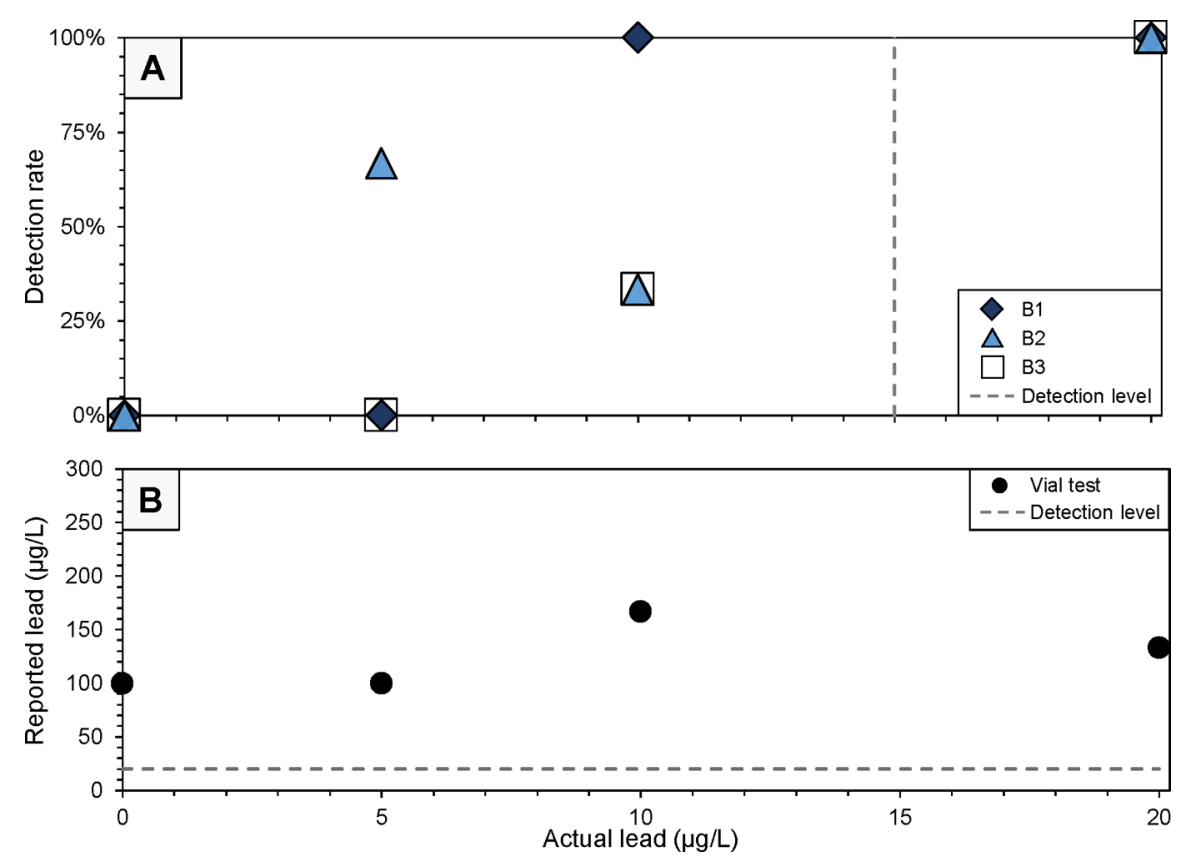

Figure 4. Test kit detection of low dissolved lead $(0,5,10$, and $20 \mu \mathrm{g} / \mathrm{L})(n=1$ participant): (A) detection rate of binary strips (positive results/ number of tests) and (B) average lead measurements from vial tests.

condition ( $n=5$ coupons per condition, $n=10$ coupons per control) for testing.

2.2.4. Validity of Binary Strip Test Kits. Sensitivity, specificity, and accuracy were calculated for all binary strip tests. Sensitivity represented the number of correctly identified positive lead results (i.e., $\geq 15 \mu \mathrm{g} / \mathrm{L}$ ) divided by the true number of positive results (true positive + false negative). Specificity represented the number of correctly identified negative lead results (i.e., $<15 \mu \mathrm{g} / \mathrm{L}$ ) divided by the true number of negative lead results (true negative + false positive). Accuracy represented the total number of correctly identified lead results divided by the total number of tests. In total, 141 tests were conducted in Phases 1-5, with 113 tests of Brand 1 and 14 tests of Brands 2 and 3 each. Seven kits were removed because of inconclusive readings. These parameters were calculated for tests exposed to only dissolved lead (Phases 1 and 2A), only particulate lead (Phase 3), and both dissolved and particulate lead (Phases 4 and 5). Results were then calculated for all binary tests $(n=134)$ considering only dissolved lead concentrations and then total lead concentrations.

2.3. Analytical Methods. Base water parameters and chlorine were analyzed using standard methods. ${ }^{23}$ To determine the concentrations of dissolved and particulate lead, a $10 \mathrm{~mL}$ filtered $(0.45 \mu \mathrm{m})$ aliquot (i.e., dissolved lead) and total lead sample (i.e., digestion in the bottle to measure all recovered lead) were analyzed. Particulate lead was defined as the difference between total lead and dissolved lead concentrations. Metal analyses of dissolved lead were performed after filtration and acidification with $2 \%$ nitric 
Table 1. Results from Phases 3 and 4: Particulate Lead Detection and Dissolution Using Weak Acids

\begin{tabular}{|c|c|c|c|c|c|c|c|c|}
\hline treatment & $\underset{(\mathrm{h})}{\mathrm{time}}$ & $\begin{array}{l}\text { particle } \\
\text { type }\end{array}$ & $\begin{array}{l}\% \text { of total recovered particle } \\
\text { mass }^{a}\end{array}$ & $\begin{array}{l}\text { total lead } \\
(\mu \mathrm{g} / \mathrm{L})\end{array}$ & $\begin{array}{l}\text { dissolved lead } \\
\quad(\mu \mathrm{g} / \mathrm{L})\end{array}$ & $\begin{array}{l}\% \text { dissolved } \\
\text { lead }\end{array}$ & $\begin{array}{l}\% \text { increase in } \\
\text { dissolution }^{b}\end{array}$ & \# positive/total \\
\hline \multirow[t]{7}{*}{ none } & \multirow[t]{7}{*}{$<0.5$} & $\mathrm{~Pb}$ & $92 \%$ & 4391.5 & 1.3 & $0 \%$ & - & $0 / 3$ \\
\hline & & $\mathrm{Al}-\mathrm{Pb}-1$ & $34 \%$ & 495.9 & 0.5 & $0 \%$ & - & $0 / 3$ \\
\hline & & $\mathrm{Zn}-\mathrm{Fe}$ & $24 \%$ & 15.0 & 0.4 & $3 \%$ & - & $0 / 3$ \\
\hline & & $\mathrm{Fe}-\mathrm{PO}_{4}$ & - & 37.3 & 2.8 & $8 \%$ & - & $0 / 3$ \\
\hline & & $\mathrm{Pb}-\mathrm{Sn}$ & $56 \%$ & 2041.8 & 33.7 & $2 \%$ & - & $3 / 3$ \\
\hline & & $\mathrm{Al}-\mathrm{Pb}-2$ & $27 \%$ & 292.0 & 0.4 & $0 \%$ & - & $0 / 3$ \\
\hline & & $\mathrm{Pb}-\mathrm{Fe}$ & $63 \%$ & 2302.5 & 15.5 & $1 \%$ & - & $3 / 3$ \\
\hline \multirow{14}{*}{$\begin{array}{r}\text { lemon } \\
\text { juice }\end{array}$} & \multirow[t]{7}{*}{1} & $\mathrm{~Pb}$ & $97 \%$ & 4466.9 & 612.7 & $14 \%$ & $14 \%$ & $3 / 3$ \\
\hline & & $\mathrm{Al}-\mathrm{Pb}-1$ & $43 \%$ & 501.1 & 70.0 & $14 \%$ & $13 \%$ & $2 / 3$ \\
\hline & & $\mathrm{Zn}-\mathrm{Fe}$ & $35 \%$ & 14.4 & 3.0 & $21 \%$ & $18 \%$ & - \\
\hline & & $\mathrm{Fe}-\mathrm{PO}_{4}$ & - & 35.7 & 34.0 & $95 \%$ & $88 \%$ & $2 / 2^{*}$ \\
\hline & & $\mathrm{Pb}-\mathrm{Sn}$ & $58 \%$ & 1781.3 & 1460.2 & $82 \%$ & $80 \%$ & $3 / 3$ \\
\hline & & $\mathrm{Al}-\mathrm{Pb}-2$ & $45 \%$ & 228.1 & 36.5 & $16 \%$ & $16 \%$ & $3 / 3$ \\
\hline & & $\mathrm{Pb}-\mathrm{Fe}$ & $79 \%$ & 2278.2 & 869.6 & $38 \%$ & $37 \%$ & $3 / 3$ \\
\hline & \multirow[t]{7}{*}{24} & $\mathrm{~Pb}$ & $97 \%$ & 4466.9 & 2782.3 & $62 \%$ & $62 \%$ & - \\
\hline & & $\mathrm{Al}-\mathrm{Pb}-1$ & $43 \%$ & 501.1 & 385.2 & $77 \%$ & $77 \%$ & - \\
\hline & & $\mathrm{Zn}-\mathrm{Fe}$ & $35 \%$ & 14.4 & 13.0 & $90 \%$ & $87 \%$ & - \\
\hline & & $\mathrm{Fe}-\mathrm{PO}_{4}$ & - & 35.7 & 35.4 & $99 \%$ & $92 \%$ & - \\
\hline & & $\mathrm{Pb}-\mathrm{Sn}$ & $58 \%$ & 1781.3 & 1698.9 & $95 \%$ & $93 \%$ & - \\
\hline & & $\mathrm{Al}-\mathrm{Pb}-2$ & $45 \%$ & 228.1 & 172.9 & $76 \%$ & $76 \%$ & - \\
\hline & & $\mathrm{Pb}-\mathrm{Fe}$ & $79 \%$ & 2278.2 & 1770.2 & $78 \%$ & $77 \%$ & - \\
\hline \multirow[t]{14}{*}{ vinegar } & \multirow[t]{7}{*}{1} & $\mathrm{~Pb}$ & $88 \%$ & 4733.4 & 435.1 & $9 \%$ & $9 \%$ & $3 / 3$ \\
\hline & & $\mathrm{Al}-\mathrm{Pb}-1$ & $39 \%$ & 591.0 & 73.4 & $12 \%$ & $12 \%$ & $3 / 3$ \\
\hline & & $\mathrm{Zn}-\mathrm{Fe}$ & $25 \%$ & 17.1 & 0.9 & $5 \%$ & $2 \%$ & - \\
\hline & & $\mathrm{Fe}-\mathrm{PO}_{4}$ & - & 34.4 & 31.7 & $92 \%$ & $85 \%$ & $2 / 2^{*}$ \\
\hline & & $\mathrm{Pb}-\mathrm{Sn}$ & $27 \%$ & 598.9 & 423.8 & $71 \%$ & $69 \%$ & $3 / 3$ \\
\hline & & $\mathrm{Al}-\mathrm{Pb}-2$ & $31 \%$ & 492.6 & 29.8 & $6 \%$ & $6 \%$ & $2 / 2^{*}$ \\
\hline & & $\mathrm{Pb}-\mathrm{Fe}$ & $63 \%$ & 1920.4 & 492.7 & $26 \%$ & $25 \%$ & $2 / 2^{*}$ \\
\hline & \multirow[t]{7}{*}{24} & $\mathrm{~Pb}$ & $88 \%$ & 4733.4 & 1111.3 & $24 \%$ & $24 \%$ & - \\
\hline & & $\mathrm{Al}-\mathrm{Pb}-1$ & $39 \%$ & 591.0 & 308.0 & $52 \%$ & $52 \%$ & - \\
\hline & & $\mathrm{Zn}-\mathrm{Fe}$ & $25 \%$ & 17.1 & 4.9 & $29 \%$ & $26 \%$ & - \\
\hline & & $\mathrm{Fe}-\mathrm{PO}_{4}$ & - & 34.4 & 31.4 & $91 \%$ & $84 \%$ & - \\
\hline & & $\mathrm{Pb}-\mathrm{Sn}$ & $27 \%$ & 598.9 & 493.8 & $83 \%$ & $81 \%$ & - \\
\hline & & $\mathrm{Al}-\mathrm{Pb}-2$ & $31 \%$ & 492.6 & 201.3 & $41 \%$ & $41 \%$ & - \\
\hline & & $\mathrm{Pb}-\mathrm{Fe}$ & $63 \%$ & 1920.4 & 926.5 & $48 \%$ & $47 \%$ & - \\
\hline
\end{tabular}

${ }^{a_{\%}}$ of total recovered particle mass could not be calculated for $\mathrm{Fe}-\mathrm{PO}_{4}$ particles because they were collected in water. ${ }^{b_{\%}}$ increase in dissolution was not calculated when no treatment was performed since this constitutes the baseline for this calculation. Dashes indicate when test kit testing was not conducted. ${ }^{*}$ Tested in triplicate, one test was invalid and not included in analysis. Pb: lead; $\mathrm{Al}$ : aluminum; Fe: iron; $\mathrm{Zn}$ : zinc; $\mathrm{Sn}$ : tin; $\mathrm{PO}$ : phosphate. Bold text denotes dissolved lead concentrations $>15 \mu \mathrm{g} / \mathrm{L}$.

acid for at least $16 \mathrm{~h}$. Total recoverable particle mass was defined as the sum of the masses of eight metals and phosphorous (Table S2) in fully digested samples (Section S2). Metal analyses for total lead and total particle mass recovered were performed after acidification in the sample bottle with $2 \%$ nitric acid and $2 \%$ hydroxylamine and heated to $60-65{ }^{\circ} \mathrm{C}$ in an oven for at least one week prior to analysis. ${ }^{24}$ Phosphorus and metals were measured using ICP-MS (Thermo Scientific iCAP RQ ICP-MS) via method 3125 B. ${ }^{23} \mathrm{QA} / \mathrm{QC}$ was performed after every 10 samples.

\section{RESULTS}

3.1. Detecting Dissolved Lead. 3.1.1. Phase 1: Detecting High Dissolved Lead. When measuring high dissolved lead in water $(150 \mu \mathrm{g} / \mathrm{L})$, users reported inaccurate lead concentrations for 12 of the 16 kits ( 11 color strip brands and 1 binary color test brand) (Figures 3 and S4; Tables S4 and S5). Users reported no lead in water with three of the color strip brands, as expected, because the dissolved lead concentration was below the lowest measurement increment of $20,000 \mu \mathrm{g} / \mathrm{L}$. However, users reported substantially more dissolved lead than was present with 8 of the 11 color strip brands, with average reported concentrations of 1700-45,000 $\mu \mathrm{g} / \mathrm{L}$ (11-300 times higher than the actual value). Users also reported lead in the blank samples for 6 of these 8 strips (mean: 16,000 $\mu \mathrm{g} / \mathrm{L}$, standard deviation (SD): 18,000 $\mu \mathrm{g} / \mathrm{L}$ ). The binary color strip did not detect lead in water, which was expected because its detection limit was $5000 \mu \mathrm{g} / \mathrm{L}$. These 12 kits did not accurately measure or detect levels of lead considered high in drinking water $(10 \times$ the US EPA action level), making them poorly applicable for drinking water testing. Because of their high detection limits, these kits were evaluated once again when exposed to extremely high particulate lead concentrations in Phase 2B (Figure 1).

Users reported detection of lead and more accurate lead concentrations with the four remaining test kits ( 1 colorimetric vial test and 3 binary strips), with an average lead concentration of $122 \mu \mathrm{g} / \mathrm{L}(\mathrm{SD}: 50 \mu \mathrm{g} / \mathrm{L})$ when using the 
colorimetric vial test. However, an average lead level of $85 \mu \mathrm{g} /$ $\mathrm{L}(\mathrm{SD}: 66 \mu \mathrm{g} / \mathrm{L}$ ) was reported in the blank, suggesting that users had problems distinguishing lead levels. The three binary strips detected lead when present, which was expected since lead concentrations were 10 times their detection threshold of $15 \mu \mathrm{g} / \mathrm{L}$. As these kits accurately measured and detected high dissolved lead, they were evaluated for detection of lower dissolved lead in Phase 2A (Figure 1).

3.1.2. Phase 2A: Detecting Low Dissolved Lead. All binary strip brands detected lead in water when exposed to $20 \mu \mathrm{g} / \mathrm{L}$ (Figure 4A), which was above the manufacturers' reported 15 $\mu \mathrm{g} / \mathrm{L}$ detection limit. Several replicates among the brands also detected lead at 10 and $5 \mu \mathrm{g} / \mathrm{L}$, highlighting some issues with their precision at low lead levels. The participant could not accurately measure low dissolved lead with the vial test, since reported measurements overestimated lead at each concentration (Figure 4B). With the vial test, the participant reported an average lead concentration of $\geq 100 \mu \mathrm{g} / \mathrm{L}$ for lead levels of 5-20 $\mu \mathrm{g} / \mathrm{L}$, including the blank. Although only one participant recorded measurements, the inability to read low lead levels was in keeping with the results from Phase 1, where six participants measured an average of $85 \mu \mathrm{g} / \mathrm{L}$ in the blank. As the participant could not accurately measure low dissolved lead, testing of the vial test was not continued. Since all binary strips performed similarly (i.e., detected low dissolved lead above their threshold), only testing of Brand 1 was continued in Phase 3 (Figure 1).

3.2. Detection of Particulate Lead. 3.2.1. Phase 2B: Detecting Extreme Concentrations of Lead Solder Particulates. None of the color strips or binary color tests could reliably detect the presence of very high particulate lead (50 $\mathrm{mg} / \mathrm{L}$ ). The lead concentration was purposefully set very high, so it was well above all reported method detection thresholds of 5 and $20 \mathrm{mg} / \mathrm{L}$. These results confirm the expectations that these kits cannot measure particulate lead. Only one replicate of the color strip detected particulate lead and that was because a lead solder particle randomly stuck to the reactive surface of the strip (Figure S5). As color strips and binary color test brands could not measure either dissolved or particulate lead at even very high concentrations for drinking water, testing was not continued (Figure 1).

3.2.2. Phase 3: Detecting Various Types of Lead Particulates. A wide array of representative water lead particles was tested with one brand of binary strip in triplicate. Despite total lead concentrations above $15 \mu \mathrm{g} / \mathrm{L}(15-4392 \mu \mathrm{g} / \mathrm{L}$; Tables 1 and S2), the binary strips only detected lead in 2 of the 7 lead particle samples $(\mathrm{Pb}-\mathrm{Sn}$ and $\mathrm{Pb}-\mathrm{Fe})$. In both of these cases, the dissolved lead concentrations were above the detection threshold ( 15 and $33 \mu \mathrm{g} / \mathrm{L}$, respectively). The binary strips failed to detect lead when exposed to the other five samples, which all had dissolved lead below the detection threshold $(0.4-2.8 \mu \mathrm{g} / \mathrm{L})$. Similar to the test kits tested in Phase 2B (Figure 1), the binary strips were unable to detect particulate lead in water.

3.3. At-Home Dissolution of Particles. 3.3.1. Lemon Juice Dissolution. Potential dissolution of lead particles using common at-home acids was explored to improve the accuracy of binary strips. Dissolution using lemon juice for $1 \mathrm{~h}$ (Tables 1 and S2) had mixed results, with dissolved lead representing $14-95 \%$ of the total lead. Almost all of the total lead in the $\mathrm{Fe}-\mathrm{PO}_{4}$ particles $(95 \%)$ dissolved after $1 \mathrm{~h}$ of lemon juice digestion. However, limited lead dissolution $(<21 \%$ of the total lead) was observed with $\mathrm{Pb}, \mathrm{Al}-\mathrm{Pb}-1, \mathrm{Zn}-\mathrm{Fe}$, and $\mathrm{Al}-\mathrm{Pb}-2$ particles. When considering the particle size (Tables S6 and $\mathrm{S} 7$ ), three particle conditions ( $\mathrm{Al}-\mathrm{Pb}-1, \mathrm{Al}-\mathrm{Pb}-2$, and $\mathrm{Zn}-\mathrm{Fe}$ ) had relatively larger particles, with $>47 \%$ of the detected particles having diameters $>10 \mu \mathrm{m}$. The other four particle conditions $(\mathrm{Pb}, \mathrm{Pb}-\mathrm{Sn}, \mathrm{Pb}-\mathrm{Fe}$, and lead solder $)$ had smaller particles, with $>91 \%$ of the particles having diameters $<10 \mu \mathrm{m}$. Conditions that initially had larger particles represent three of the four conditions with limited lead dissolution, whereas greater lead dissolution was found in most conditions with smaller particles, as per expectations. ${ }^{25}$ When dissolved lead levels increased above the $15 \mu \mathrm{g} / \mathrm{L}$ detection threshold, test kits correctly detected the presence of elevated lead in water. Dissolution using lemon juice facilitated the detection of five previously undetected lead particles in this study. Binary strip testing for the $\mathrm{Zn}-\mathrm{Fe}$ particle was not conducted because the total lead concentration was less than $15 \mu \mathrm{g} / \mathrm{L}$, but lemon juice digestion did increase dissolved lead levels by $20.8 \%$. Increasing the lemon juice digestion time to $24 \mathrm{~h}$ further increased dissolved lead concentrations from an average (range) of $40 \%(14-95 \%)$ after $1 \mathrm{~h}$ to $83 \%$ (62-99\%) after $24 \mathrm{~h}$.

3.3.2. Vinegar Dissolution. When exposed to vinegar for $1 \mathrm{~h}$ (Tables 1 and S2), dissolved lead represented 5-92\% of the total lead. As before, $92 \%$ of the total lead in $\mathrm{Fe}-\mathrm{PO}_{4}$ particles dissolved, whereas $<12 \%$ of the total lead in $\mathrm{Pb}, \mathrm{Al}-\mathrm{Pb}-1, \mathrm{Zn}-$ $\mathrm{Fe}$, and $\mathrm{Al}-\mathrm{Pb}-2$ particles dissolved after $1 \mathrm{~h}$ of vinegar dissolution. Dissolved lead concentrations increased from an average (range) of $32 \%(5-92 \%)$ after $1 \mathrm{~h}$ to an average of $52 \%(24-91 \%)$ after $24 \mathrm{~h}$. Again, these results demonstrated that at-home treatment with vinegar improved the ability of the binary strip to detect particulate lead for five of the particulate conditions. However, dissolution with lemon juice consistently yielded greater lead dissolution compared with vinegar treatment, which is likely due to the lower $\mathrm{pH}$ achieved with lemon juice treatment $(\mathrm{pH} 3)$ compared with vinegar $(\mathrm{pH}$ 3.5).

3.4. Case Study: Detection of Lead Solder Particles Formed in Varying CCT Waters. The accuracy and precision of binary strips were examined using lead particles generated when lead solder joints were exposed to five different corrosion control treatments (Tables S8 and S9). Binary strips detected lead in the controls, polyphosphate, and polyphosphate with nitrate conditions, which had dissolved lead above the detection threshold (130.2-443.6 $\mu \mathrm{g} / \mathrm{L})$. However, binary strips did not detect lead in the orthophosphate or orthophosphate/polyphosphate blend conditions because of the low dissolved lead (2.5 and 4.8 $\mu \mathrm{g} / \mathrm{L})$, despite the total lead being above the detection threshold (20.1 and $17.2 \mu \mathrm{g} / \mathrm{L})$. Binary strips correctly indicated no lead in the zinc orthophosphate condition when the total lead was below $15 \mu \mathrm{g} / \mathrm{L}$. Overall, binary strips detected lead in 4 of the 6 conditions where the total lead exceeded the detection threshold of $15 \mu \mathrm{g} / \mathrm{L}$.

Lemon juice treatment increased the percent of total lead that was dissolved in controls, polyphosphate, and polyphosphate with nitrate condition (10-63 to 91-95\%), thereby producing higher dissolved lead concentrations (185.5-530.3 $\mu \mathrm{g} / \mathrm{L})$. However, these conditions had high enough dissolved lead without digestion to facilitate binary strip detection. As expected, binary strips did not detect lead in the orthophosphate or orthophosphate/polyphosphate blend conditions where the total lead was below $15 \mu \mathrm{g} / \mathrm{L}$. However, lead dissolution increased with lemon juice treatment from 
$13-28$ up to $67 \%$ of the total lead, suggesting this treatment would improve detection with binary strips if high enough total lead was present. As before, the use of at-home digestion increased the dissolution of lead, which tended to improve the accuracy of the binary strips.

3.5. Binary Strip Accuracy. Binary strips' inability to detect particulate lead resulted in lower sensitivity, specificity, and accuracy (Table S10). Binary strips were $82.1 \%$ accurate when testing water with only dissolved lead (Phases 1 and 2A), but only $28.6 \%$ accurate when testing water with only particulate lead (Phase 3). When water contained both dissolved and particulate lead (Phases 4 and 5), the accuracy increased to $89.2 \%$. Overall, in Phases $1-5$ binary strips had a $77.6 \%$ accuracy rate for total lead detection and $93.3 \%$ for dissolved lead detection. Increases in sensitivity and specificity were also observed when comparing detection based on total lead versus dissolved lead (total lead: sensitivity $77.2 \%$, specificity $78.8 \%$; dissolved lead: sensitivity $97.5 \%$, specificity $87.0 \%)$. These results further underscore the limitations of binary strips in detecting particulate lead.

The relatively high false negative rates observed in Phases 4 and $5(10.8 \%)$ and overall $(17.2 \%)$ may also be concerning because these indicate kits reporting no lead when total lead concentrations were actually $>15 \mu \mathrm{g} / \mathrm{L}$. While a high false negative rate $(71.4 \%)$ was expected for particulate lead (Phase 3 ), clearly such problems also extend to situations with a mixture of dissolved and particulate lead. Overall, binary strip sensitivity, specificity, and accuracy at measuring dissolved lead in this study were relatively high, but lower accuracy, sensitivity, and specificity should be expected in situations where particulate lead is more prevalent. Future efforts should focus on either reducing such errors or considering how this error affects usefulness of the tests.

\section{IMPLICATIONS}

4.1. Engaging, Equipping, and Empowering Consumers in the LCR's Shared Responsibility Framework. The 1991 LCR was never designed to protect all residents from elevated lead in drinking water, but instead created a shared responsibility between consumers and their water suppliers for mitigating lead in water exposure. ${ }^{6,9,18}$ Water utilities are responsible for water quality targets for "optimal" corrosion control, regulatory monitoring of a few homes, removal of utility-owned lead service lines, and public education. Consumers share some responsibilities since lead in drinking water partly results from lead in privately owned building plumbing. However, traditionally, implementation of the LCR has focused almost exclusively on water utilities' responsibilities, and such utility-centric frameworks cannot fully address issues with lead in drinking water without engaging consumers. ${ }^{1,3,4,22}$ Likewise, private water systems (e.g., wells, springs) are not regulated by the US EPA, and in these cases, the sole responsibility for the detection and mitigation of lead falls on consumers. ${ }^{26}$ It is necessary to provide consumers with the tools and resources to identify lead in drinking water risks when present and instructions for protective interventions.

The availability of affordable, reliable, and accurate lead in water test kits could help residents identify water hazards and, in the aftermath of Flint, there are many new tests under development. While many existing at-home lead in water test kits are available, most were ineffective at detecting or measuring lead at drinking water levels. Binary strips, especially when coupled with at-home weak acid dissolution, reliably detected dissolved lead concentrations above $15 \mu \mathrm{g} / \mathrm{L}$, suggesting that these kits show a lot of promise. However, only detecting lead above the existing $15 \mu \mathrm{g} / \mathrm{L}$ detection threshold may render these kits quickly obsolete, as many organizations are pushing for lower recommended lead in water levels, such as the $1 \mu \mathrm{g} / \mathrm{L}$ goal of the American Association of Pediatrics which has influenced policy decisions, interventions, and consumer expectations. ${ }^{27}$ The test methodology developed herein could be used as a framework for vetting the new water lead test kits by developers.

4.2. Particulate Lead is an Emerging Problem in Drinking Water. Lead particles from solder and pipe scales are an important source of lead exposure in drinking water $^{19,28-30}$ that was not well quantified by at-home test kits. This is problematic because numerous cases of lead poisoning have been linked to ingestion of lead particles ${ }^{1,4}$ and many lead problems in the US are being attributed to the mobilization of particles. ${ }^{19}$ In some cases, the likely presence of lead particles may be associated with discoloration, as was demonstrated through the association of higher lead concentrations with discolored water because of high cooccurring levels of iron (e.g., Flint water crisis). ${ }^{22,24}$ However, iron and lead do not always co-occur in drinking water and, in many cases, lead particles are not visible to the naked eye (e.g., Washington, DC Lead Crisis), ${ }^{1}$ underscoring the importance of testing. As with other testing procedures, ${ }^{7,11,12}$ at-home test kits in this study failed to detect particulate lead, yielding false negative results.

Digestion with acids is needed to dissolve lead particles, and household acids promoted enough dissolution of some lead particles to improve the binary strip detection of particulate lead. In addition to particle composition, variations in particle dissolution and the fraction of total recoverable particle mass may be related to unaccounted for particle constituents, as well as variations in observed particle size and surface area. ${ }^{25}$ As expected, in this study, smaller particles generally exhibited greater dissolution than larger particles. Some lead particles (e.g., lead(IV) oxides and lead phosphates) have been reported to be insoluble in weak acid, whereas others (e.g., lead(II) oxides) are reported to be more readily dissolved. ${ }^{9,28,31}$ Lemon juice and vinegar have been used to dissolve rust and metals ${ }^{32}$ and may improve dissolution by lowering the $\mathrm{pH}$ of the solution $(\mathrm{pH} 3-3.5)$. Although the mineralogical identity of particles was not determined, lead phosphates were likely present in some particles as evidenced by phosphate $>20 \%$ of the identified particle mass. The use of either vinegar or lemon juice for $24 \mathrm{~h}$ increased dissolved lead (relative to the total lead) by $41-92 \%$ for these particles. The relative ease with which lead particles in this study dissolved in weak acids suggests that some particles previously thought to be relatively recalcitrant may be more susceptible to dissolution in weak organic acids than previously thought. Therefore, at-home dissolution procedures may represent a relatively safe method to improve binary strip test kit performance in detecting particulate lead, reducing one of the main problems of at-home lead in water test kits.

4.3. Strengths and Weaknesses of Binary Strips. This study demonstrated the critical weaknesses of some test kits, such as overestimation of lead concentrations and detection limits that exceed a drinking water-relevant range for a majority of color-based test kits. Binary strips correctly indicated whether dissolved lead concentrations were above the $15 \mu \mathrm{g} / \mathrm{L}$ threshold in $93 \%$ of the tests in this study, but failure to detect 
particulate lead was a weakness of the binary strips. At-home dissolution with lemon juice or vinegar dissolved many particles enough to increase dissolved lead concentrations to $>15 \mu \mathrm{g} / \mathrm{L}$, allowing for detection of these particles. These results demonstrate that binary strips may present a somewhat accurate and relatively low-cost option ( $\$ 13-\$ 40$ per test) for at-home testing. Future development focused on reducing the cost burden of lead testing, as exemplified by a goal to reduce at-home arsenic testing costs to as low as $\$ 0.21$ per test, ${ }^{33}$ could increase accessibility.

Lead in water test kits, similar to at-home arsenic tests, could benefit from improved ease of use, safety, accuracy, improved detection limits, and clear endpoints for easy interpretation. ${ }^{33-35}$ Kits should include information about stagnation protocols, sample volumes, and flow rates, which are known sources of error/variation for lead sampling ${ }^{28,36,37}$ as well as any additional dissolution steps or updates on regulatory or public health changes that affect the interpretation of results. For example, studies of similar binary strips for atrazine indicated that binary strips may require improvements in instructional materials or training to allow citizen scientists to more accurately determine results. ${ }^{38}$ There is currently no certification authority to ensure accuracy of at-home lead in water test kits. In light of this, the sensitivity, specificity, and accuracy of all test kits needs to be verified under real-world conditions.

\section{ASSOCIATED CONTENT}

\section{SI Supporting Information}

The Supporting Information is available free of charge at https://pubs.acs.org/doi/10.1021/acs.est.0c07614.

Details of lead particle source and composition; test kit selection, performance, and types of kits; particle size characterization; lead and metals results for all experiments; and description of user confidence results (PDF)

\section{AUTHOR INFORMATION}

\section{Corresponding Authors}

Kelsey J. Pieper - Civil and Environmental Engineering,

Northeastern University, Boston, Massachusetts 02115,

United States; (1) orcid.org/0000-0002-0273-6527;

Email: k.pieper@northeastern.edu

Marc A. Edwards - Civil and Environmental Engineering, Virginia Tech, Blacksburg, Virginia 24061, United States; ○ orcid.org/0000-0002-1889-1193; Email: edwardsm@ vt.edu

\section{Authors}

Rebecca Kriss - Civil and Environmental Engineering, Virginia Tech, Blacksburg, Virginia 24061, United States; (1) orcid.org/0000-0002-7270-7078

Jeffrey Parks - Civil and Environmental Engineering, Virginia Tech, Blacksburg, Virginia 24061, United States

Complete contact information is available at:

https://pubs.acs.org/10.1021/acs.est.0c07614

\section{Notes}

The authors declare no competing financial interest.

\section{ACKNOWLEDGMENTS}

This research was supported by a grant from the U.S. Environmental Protection Agency (US EPA) "Untapping the
Crowd: Consumer Detection and Control of Lead in Drinking Water" (\#8399375) and Spring Point Partners LLC. The opinions expressed in this report are those of the author(s) and do not necessarily reflect the views of Spring Point Partners LLC or the US EPA. This work used shared facilities at the Virginia Tech National Center for Earth and Environmental Nanotechnology Infrastructure (NanoEarth), a member of the National Nanotechnology Coordinated Infrastructure (NNCI), supported by NSF (ECCS 1542100).

\section{REFERENCES}

(1) Edwards, M.; Triantafyllidou, S.; Best, D. Elevated Blood Lead in Young Children Due to Lead-Contaminated Drinking Water: Washington, DC, 2001-2004. Environ. Sci. Technol. 2009, 43, $1618-1623$.

(2) Brown, M. J.; Raymond, J.; Homa, D.; Kennedy, C.; Sinks, T. Association between Children's Blood Lead Levels, Lead Service Lines, and Water Disinfection, Washington, DC, 1998-2006. Environ. Res. 2011, 111, 67-74.

(3) Hanna-Attisha, M.; LaChance, J.; Sadler, R. C.; Champney Schnepp, A. Elevated Blood Lead Levels in Children Associated with the Flint Drinking Water Crisis: A Spatial Analysis of Risk and Public Health Response. Am. J. Public Health 2016, 106, 283-290.

(4) Edwards, M.; Triantafyllidou, S. Chloride-to-Sulfate Mass Ratio and Lead Leaching to Water. J.-Am. Water Works Assoc. 2007, 99, 96-109.

(5) Olson, E. D.; Pullen Fedinick, K. What's in Your Water Flint and beyond; Natural Resources Defense Council: New York, NY, 2016. https://www.nrdc.org/sites/default/files/whats-in-your-water-flintbeyond-report.pdf (accessed July 1, 2020).

(6) Katner, A.; Pieper, K. J.; Lambrinidou, Y.; Brown, K.; Hu, C.-Y.; Mielke, H. W.; Edwards, M. A. Weaknesses in Federal Drinking Water Regulations and Public Health Policies That Impede Lead Poisoning Prevention and Environmental Justice. Environ. Justice 2016, 9, 109117.

(7) Triantafyllidou, S.; Nguyen, C. K.; Zhang, Y.; Edwards, M. A. Lead $(\mathrm{Pb})$ Quantification in Potable Water Samples: Implications for Regulatory Compliance and Assessment of Human Exposure. Environ. Monit. Assess. 2013, 185, 1355-1365.

(8) U.S. EPA. Maximum Contaminant Level Goals and National Primary Drinking Water Regulations for Lead and Copper; Final Rule. Fed. Regist. 1991, 56, 26460.

(9) Triantafyllidou, S.; Edwards, M. Lead (Pb) in Tap Water and in Blood: Implications for Lead Exposure in the United States. Crit. Rev. Environ. Sci. Technol. 2012, 42, 1297-1352.

(10) Doré, E.; Lytle, D. A.; Wasserstrom, L.; Swertfeger, J.; Triantafyllidou, S. Field Analyzers for Lead Quantification in Drinking Water Samples. Crit. Rev. Environ. Sci. Technol. 2020, 1-32.

(11) Cartier, C.; Bannier, A.; Pirog, M.; Nour, S.; Prevost, M. A Rapid Method for Lead Service Line Detection. J.-Am. Water Works Assoc. 2012, 104, E596-E607.

(12) Schock, M. R.; George, G. K. Evaluation of a Field Test Kit for Monitoring Lead in Drinking Water. J.-Am. Water Works Assoc. 1993, 85, 90-100.

(13) Deshommes, E.; Bannier, A.; Laroche, L.; Nour, S.; Prévost, M. Monitoring-Based Framework to Detect and Manage Lead Water Service Lines. J.-Am. Water Works Assoc. 2016, 108, E555-E570.

(14) The Good Housekeeping Institute. Home Water Tests: The Claims, The Truth; Good Housekeeping Institue, February 15, 2012. http://www.goodhousekeeping.com/health-products/a18919/watertests/ (accessed July 1, 2020).

(15) Sweigart, M. Best Water Test Kit-2020 Buyers Guide; The Safe Healthy Home, June 28, 2020. https://thesafehealthyhome.com/ best-home-water-test-kit-review/ (accessed July 1, 2020).

(16) Pierce, G.; Gonzalez, S. Mistrust at the Tap? Factors Contributing to Public Drinking Water (Mis)Perception across US Households. Water Policy 2017, 19, 1-12. 
(17) Rosinger, A. Y.; Young, S. L. In-home Tap Water Consumption Trends Changed among US Children, but Not Adults, between 2007 and 2016. Water Resour. Res. 2020, 56, e2020WR027657.

(18) Pieper, K. J.; Katner, A.; Kriss, R.; Tang, M.; Edwards, M. A. Understanding Lead in Water and Avoidance Strategies: A United States Perspective for Informed Decision-Making. J. Water Health 2019, 17, 540-555.

(19) Deshommes, E.; Prévost, M. Pb Particles from Tap Water: Bioaccessibility and Contribution to Child Exposure. Environ. Sci. Technol. 2012, 46, 13559-13560.

(20) NSF International Standard/American National Standard. NSF/ANSI 61-Drinking Water System Components-Health Effects, 2015.

(21) St. Clair, J.; Cartier, C.; Triantafyllidou, S.; Clark, B.; Edwards, M. Long-Term Behavior of Simulated Partial Lead Service Line Replacements. Environ. Eng. Sci. 2016, 33, 53-64.

(22) Pieper, K. J.; Tang, M.; Edwards, M. A. Flint Water Crisis Caused By Interrupted Corrosion Control: Investigating "Ground Zero" Home. Environ. Sci. Technol. 2017, 51, 2007-2014.

(23) American Public Health Association, American Water Works Association, Water Environment Federation. Standard Methods for Examination of Water and Wastewater, 20th ed.; American Public Health Association: Washington, D.C., 1998.

(24) Masters, S.; Edwards, M. Increased Lead in Water Associated with Iron Corrosion. Environ. Eng. Sci. 2015, 32, 361-369.

(25) Ruby, M. V.; Davis, A.; Kempton, J. H.; Drexler, J. W.; Bergstrom, P. D. Lead Bioavailability - Dissolution Kinetics under Simulated Gastric Conditions. Environ. Sci. Technol. 1992, 26, 12421248.

(26) Pieper, K. J.; Krometis, L.-A. H.; Gallagher, D. L.; Benham, B. L.; Edwards, M. Incidence of Waterborne Lead in Private Drinking Water Systems in Virginia. J. Water Health 2015, 13, 897-908.

(27) Parks, J.; Pieper, K. J.; Katner, A.; Tang, M.; Edwards, M. Potential Challenges Meeting the American Academy of Pediatrics' Lead in School Drinking Water Goal of $1 \mu \mathrm{g} / \mathrm{L}$. Corrosion 2018, 74, 914-917.

(28) Triantafyllidou, S.; Parks, J.; Edwards, M. Lead Particles in Potable Water. J.-Am. Water Works Assoc. 2007, 99, 107-117.

(29) Edwards, M.; Dudi, A. Role of Chlorine and Chloramine in Corrosion of Lead-Bearing Plumbing Materials. J.-Am. Water Works Assoc. 2004, 96, 69-81.

(30) Mcneill, L. S.; Edwards, M. Importance of $\mathrm{Pb}$ and $\mathrm{Cu}$ Particulate Species for Corrosion Control. J. Environ. Eng. 2004, 130, 136-144.

(31) Cao, X.; Ma, L. Q.; Singh, S. P.; Zhou, Q. Phosphate-Induced Lead Immobilization from Different Lead Minerals in Soils under Varying PH Conditions. Environ. Pollut. 2008, 152, 184-192.

(32) Hewitt, K. Natural Rust Remedies; Farmer's Almanac, July 13, 2009. https://www.farmersalmanac.com/rust-remedies-10777 (accessed August 31, 2020).

(33) Lizardi, C. L. "Penny per Test" - Low Cost Arsenic Test Kits. Mobilizing Chemistry Expertise to Solve Humanitarian; American Chemical Society, 2017; pp 51-61.

(34) Arora, M.; Megharaj, M.; Naidu, R. Arsenic Testing Field Kits: Some Considerations and Recommendations. Environ. Geochem. Health 2009, 31, 45-48.

(35) Spear, J. M.; Zhou, Y. M.; Cole, C. A.; Xie, Y. F. Evaluation of Arsenic Field Test Kits for Drinking Water Analysis. J.-Am. Water Works Assoc. 2006, 98, 97.

(36) Cartier, C.; Laroche, L.; Deshommes, E.; Nour, S.; Richard, G.; Edwards, M.; Prévost, M. Investigating Dissolved Lead at the Tap Using Various Sampling Protocols. J.-Am. Water Works Assoc. 2011, $103,55-67$

(37) Clark, B.; Masters, S.; Edwards, M. Profile Sampling to Characterize Particulate Lead Risks in Potable Water. Environ. Sci. Technol. 2014, 48, 6836-6843.

(38) Ali, J. M.; Noble, B. C.; Nandi, I.; Kolok, A. S.; Bartelt-Hunt, S. L. Assessing the Accuracy of Citizen Scientist Reported Measure- ments for Agrichemical Contaminants. Environ. Sci. Technol. 2019, 53, 5633-5640. 